\title{
REVISÃO
}

\section{SAÚDE PÚBLICA: A MEDICINA E A POLÍTICA}

\author{
Francisco Itami Campos ${ }^{1}$
}

\begin{abstract}
A medicina social (...) é necessariamente politica. $O$ que não significa que ela seja um contra-poder ou um poder paralelo. Ela é politica tanto pelo modo como intervém na sociedade e penetra em suas instituições, como pela sua relação com o Estado. Ela precisa do Estado para realizar seu projeto de prevenção das doenças da população. Sem instrumento de poder próprio ela é ineficaz e vã. E, ao mesmo tempo, ela é útil ao Estado por ser um instrumento especializado capaz de assumir com ele e por ele as questões relativas à saúde, trazendo-lhe o apoio de uma ciência.(...) (Machado, 1978, p. 242).
\end{abstract}

\section{RESUMO}

A transformação da medicina nos séculos XVIII e XIX na sua forma de conhecimento sobre o homem, torna-a mais abrangente - meio ambiente, a natureza, a sociedade - uma-preocupação mais social, e tornando-a uma ciência do social. O saber médico como instrumento de poder e de legitimação. Vai ser na saúde pública que o saber médico se explicita como obtenção de conhecimento do social e como dominação. Para explicitar esse processo, trabalha-se com a 'criação' do serviço sanitário em Goiás (1920/1940), procurando evidenciar como a medicina intervém na sociedade, estabelece um controle político e é utilizada como elemento de poder.

UNITERMOS: Saúde pública. Medicina. Política.

\section{INTRODUÇÃO}

Muitos são os que dizem não haver relação entre medicina e política. A base da argumentação é que ambas situam-se em campos de conhecimento distintos e que tratam de atividades que têm pouco a ver entre si. O que se pretende neste trabalho é demonstrar exatamente o contrário desta posição, ou seja, que a medicina tem estreitado sua relação com o poder, com o Estado, na sua constituição e na sua afirmação como ciência.

${ }^{1}$ Professor de Ciência Política, Departamento de Ciências Sociais/Faculdade de Ciências Humanas e Filosofia da Universidade Federal de Goiás. Doutor em Política, USP.

Recebido para publicação em 26/12/96. 
Em $O$ nascimento da clínica, Michel Foucault procura mostrar o que chama de o 'novo olhar' da medicina - processo de formação e de constituição do saber médico, na França. Quando trata das epidemias, mostra como a análise delas leva a medicina a se aproximar do Estado, tanto na busca de um maior conhecimento como no controle da profissão, regulando o seu exercício e procurando impedir que práticos e charlatães exerçam a medicina.

Também em $A$ danação da norma, os autores salientam a importância que adquire a ciência médica, quando os médicos oferecem assessoria à Câmara Municipal com o objetivo de sanear a cidade do Rio de Janeiro, então sede do Império. Ao mesmo tempo em que intervêm na cidade e elaboram as normas de higiene e o código de postura, estabelecem controles para o exercício da medicina e formas de combate ao charlatanismo e à homeopatia.

No artigo Mudança da capital: uma estratégia de poder, analiso a mudança da capital do Estado da cidade de Goiás para Goiânia. No trabalho fica evidente a utilização do saber médico, via regulamento da saúde pública, pelo interventor Pedro Ludovico.

Procuro, neste momento, ver a importância do saber médico e sua proximidade com a política, e, por isso, não retomo os argumentos daquele trabalho quanto às cidades. Destaco, contudo, os governos em que se define uma política para a saúde pública estadual - o de Brasil Ramos Caiado e o de Pedro Ludovico Teixeira. Nestes, ocorrem os momentos de 'criação' da saúde pública na estrutura governamental do Estado; em ambos, os governadores eram médicos. É de se indagar se existe um interesse próprio da atividade deles, enquanto médicos, ou se esse interesse extrapola para questões políticas que envolveriam a busca de legitimidade, de controle e de formas de afirmação política.

A questão da saúde pública foi debatida no país desde o início da República, em vários congressos e encontros nacionais, realizados em diferentes lugares. Alguns Estados, ainda no começo da República, mantêm um serviço regular de saúde pública. São poucas as obras que tratam desta temática e que se referem ao período anterior a 1930, exceção feita a Machado et alli (1978) e a Merhy (1992). O primeiro, no livro já clássico no tratamento do tema, aborda as origens do que viria a se tornar uma política médica, no Rio de Janeiro, no século XIX. O segundo, na intenção de analisar a saúde pública em São Paulo, apresenta um pouco do debate nacional na Primeira República - conforme o autor, até 1930 a saúde pública era quase restrita a aspectos sanitaristas. Os debates e seminários havidos giravam em torno de questões sanitárias.

Se em nível nacional havia algum debate, em Goiás, até então, a temática não era discutida. Somente em 1926 é que vai ser implementado o Serviço Sanitário do Estado. O governador, em mensagem à Câmara dos Deputados, em 1927, afirma que a falta de tal serviço constitui uma "deplorável omissão" na organização administrativa, situação agravada, como diz adiante, pela existência de órgãos análogos em outros Estados. Adiante discute-se a instalação do serviço sanitário e sua importância política.

\section{A MEDICINA E A POLÍTICA}

Torna-se importante falar das transformações radicais que a medicina sofreu nos séculos XVIII e XIX, tanto na sua forma de compreensão e apreensão do conhecimento quanto no seu modo de intervenção. $O$ objeto desta nova medicina se desloca da doença para a saúde. Ela vai representar um novo conhecimento sobre o homem e não somente sobre ele, pois torna-se mais abrangente o seu objeto de conhecimento. Este passa a englobar também o meio ambiente, a natureza e a sociedade em que o homem vive, daí uma maior preocupação com o social - a medicina passa a ser uma ciência do social. Esta nova medicina muda também seu modo de intervenção: penetra na sociedade e em suas instituições, vasculha lugares e ocupações que até então the eram alheios. E, no esquadrinhamento que realiza, intervém em todos os espaços e se torna política.

Discutindo a origem da medicina moderna, Foucault trabalha a hipótese de que o capitalismo socializou o corpo enquanto força de produção, de trabalho. "O controle da sociedade sobre os indivíduos não se opera simplesmente pela consciência ou pela ideologia, mas começa no corpo, com o corpo. Foi no biológico, no somático, no corporal que, antes de tudo, investiu a sociedade capitalista. O corpo é uma realidade bio-política. A medicina é uma estratégia bio-política" (Foucault, 1979, p. 80).

Desenvolvendo esse processo de socialização, Foucault reconstitui o que chama de três etapas na formação da medicina social. À primeira, denomina medicina do Estado, em que procura caracterizar o Estado moderno na Alemanha do século XVIII, especialmente o que chama de "normalização dos médicos": "Com a organização de um saber médico estatal, a normalização da profissão médica, a subordinação dos médicos a uma administração central e, finalmente, a integração de vários médicos em uma organização médica estatal, tem-se uma série de fenômenos inteiramente novos que caracterizam o que pode ser chamada a medicina de Estado" (Foucault, 1979, p. 84). Na segunda, a medicina urbana, ele analisa o seu desenvolvimento como um poder político capaz de esquadrinhar a população e o urbano: uma medicina das coisas - ar, água, decomposições, fermentos -, uma medicina das condições de vida e do meio de existência (Foucault, 1979, p. 92). Para ele, a terceira etapa ocorre sobretudo na Inglaterra do século XIX. A esta, ele denomina medicina da força de trabalho. Segundo o autor, o específico deste momento é um controle da saúde e do corpo das classes mais pobres de tal modo a torná-las mais aptas ao trabalho e menos perigosas às classes mais ricas (Foucault, 1979, p. 97). 
CAMIOS, 1. 1. Saude Pública: a medicina e a política. Rev. Pat. Trop.25 (2 ): 173-186, jul./dez. 1996

Toda essa transformação da medicina é resultado de um longo processo no qual a acumulação de conhecimento e conseqüente intervenção ocorrem simultaneamente. A intervenção se dá através da polícia médica, constituída dos seguintes itens: a) existência de um órgão dirigente da saúde pública; b) esquadrinhamento urbano; c) assistencialismo; d) inspeção sanitária; e) fiscalização do exercício da medicina e das farmácias; f) registro médico, que permite acumular mais informações, possibilitando maior conhecimento da sociedade e aumentando sua capacidade de intervenção (Machado, 1978, p. 244/45). A polícia médica usa os seguintes procedimentos como forma de obtenção de conhecimento e como meio de controle: organização de estatísticas sobre a população; controle sobre os indivíduos; definição da cidade como seu espaço de atuação; controle de epidemias; e criação de autoridade médica ligada à administração estatal e responsável pela higiene e saúde pública. O discurso que fundamenta o saber médico tem por base um conhecimento que está ao alcance somente do especialista. Este não é um conhecimento isolado, tendo por base a observação da sociedade, pois busca em outras ciências elementos que permitam uma maior caracterização do clima, do meio ambiente, da natureza e do homem, em particular. Neste sentido é que a medicina se torna social. Vale mencionar que esses itens que caracterizam a polícia médica tornam-se as bases dos regulamentos de saúde pública.

Alguns estudiosos vêem na questão do saber médico e no médico formas de controle. Entre esses, destaca-se Augusto Comte, um dos fundadores da sociologia, que busca na medicina não somente a sua concepção de normal/patológico para aplicar à ordem social, mas também a sua terapêutica. Na sua visão conservadora, procura conter as ideologias revolucionárias através de novas bases teóricas capazes de defender a ordem estabelecida e estas têm origem na medicina. Conforme uma estudiosa, Comte vai mais além, pois para ele os médicos deveriam ser "os dirigentes políticos da nova sociedade, cientificamente organizada; o poder político é o prolongamento da ascendência que o médico exerce sobre o indivíduo: poder desinteressado, exercido em nome da verdade e como tal livremente aceito..." (Carrion, 1981, p. 42).

Para ela, esta temática do poder tendo por base o saber remete à discussão da legitimidade: "Colocada a nível do saber, a questão do poder e da autoridade escapa 'ipso facto' à competência da maioria, tornando-se prerrogativa de especialistas" (Carrion, 1981, p. 43).

$\mathrm{O}$ saber médico se afirma nos regulamentos, enquanto normatiza a vida e o cotidiano da cidade e do cidadão, ao mesmo tempo em que, via delegacias de higiene e classe médica, procura melhor conhecer a realidade. É o dispositivo do saberpoder. As estatísticas, os levantamentos da situação médico-sanitária, as informações sobre as condições de vida da população, porquanto permitem um conhecimento mais especifíco, mais próximo, realimentam o saber médico, utilizado pelas estruturas de poder como forma de dominação. O poder permite conhecer, 0 conhecimento reforça o poder, a dominação.

O conceito de dominação comporta um caráter instrumental e, numa perspectiva histórica, ela se expressa no Estado, considerado como organização e como aparato de poder que, na maioria dos casos, coloca-se a serviço de uma dada classe. Quando estuda poder e dominação, Max Weber trabalha a segunda como se expressando em 'regime de governo'. Toda dominação, afirma, manifesta-se na forma de governo. Todo regime de governo necessita do domínio de algum modo, pois, para seu desempenho, sempre deve colocar em mãos de alguém poderes imperativos (Weber, 1968, 701).

Dominação aqui é entendida numa perspectiva relacional e não como algo abstrato, distante. Seu caráter relacional faz com que o poder implique uma prática cotidiana, uma interferência no dia-a-dia da população. E ela se expressa não somente pela interdição, pela proibição. Ela é, em muitos momentos, marcada por aspectos positivos, construtivos.

O exemplo que tomo para caracterizar este processo de relacionamento da medicina com a política é um período da história de Goiás, que vai do final da Primeira República até o início do Estado Novo. Melhor dizendo, são dois momentos de 'criação' do Serviço Sanitário ou de Higiene no Estado de Goiás: o primeiro, no governo de Brasil Ramos Caiado, 1924-1929; o segundo, no governo de Pedro Ludovico, 1930-1938.

Em ambos os momentos, o médico é chamado a desempenhar uma função importante na administração pública. Os regulamentos da saúde pública atribuem a esses profissionais um destacado papel; eles passam a ser dirigentes, através do conhecimento técnico que detêm. São colocados em destaque no Estado e nas municipalidades, pois através do serviço sanitário, via regulamentos, podem intervir e controlar o Estado como um todo, os espaços urbanos e rurais, o trabalho e o lazer, a vida e a morte. O Regulamento de 1931 é sutil ao alertar a 'classe médica' para que faça o controle não por medidas coercitivas "que vão cedendo seu lugar sob a influência da obra inteligente da educação sanitária" (Goyaz, Regulamento, 1931, p.10).

\section{SAUDE PÚBLICA: o Serviço Sanitário}

\subsection{Antes de 1930}

No governo Brasil Caiado, 1924-1929, a ordem oligárquica que se impôs a partir de 1912, com a dominação Caiado-Castro-Jardim, se vê diante de sérias perturbações. A primeira tem na Coluna Prestes seu ponto principal. Durante mais de um ano, ela percorre o território goiano pregando a mudança do regime $\mathrm{e}$ confrontando a autoridade constituída. A classe dirigente goiana é mobilizada pelo senador 'Totó' Caiado, que organiza um batalhão de defesa do Estado e que tem o objetivo de combater os revoltosos. A segunda é a "questão do judiciário". O 
Superior Tribunal de Justiça, órgão máximo da justiça estadual, por se reconhecer sem condiçôes de funcionamento, e alegando interferência do governo em questões especificas da justiça, pede intervenção federal para Goiás. A terceira é de ordem politica e diz respeito ao surgimento de oposição ao grupo dominante, marcada também pela dissensão no grupo político situacionista. Desde 1917, praticamente nđo havia oposição ao caiadismo. No governo Brasil Caiado, um grupo de políticos da capital organiza um partido de oposição, que tem no jornal $\mathrm{Voz}$ do Povo seu ponto de aglutinação. Além disso, no sudoeste ocorre uma dissidência no situacionismo, que vai ser o principal suporte político de Pedro Ludovico no pós-1930.

O governo federal, diante do quadro político goiano, teria, conforme algumas fontes, imposto como forma de acordo para a solução da "crise do judiciário" que a sucessão de Brasil Caiado ocorresse fora da família Caiado, isto para não considerar o pedido de intervenção protocolado pelo STJ goiano junto ao governo federal. Daí a candidatura de Alfredo Lopes de Moraes e sua tranqüila investidura no governo estadual.

Referindo-se à questão orçamentária do período, Campos observa que os gastos estatais refletem sempre o estabelecimento do controle e a manutenção da ordem, vez que a força pública, a justiça e o fisco consomem uma média de 54,9\% dos gastos orçamentários em toda República Velha (Campos, 1983, p. 65). Na gestão Brasil Caiado, contudo, ocorre uma ligeira modificação deste quadro pois aumentam os gastos orçamentários com educação e com obras públicas e destinam-se os primeiros recursos para a saúde pública. Ao que parece, o governo goiano procura, desta forma, maior legitimação e apoio.

Em 1926, no governo do médico Brasil Ramos Caiado, é instalado o Serviço Sanitário em Goiás, criado no ano anterior. Como afirma o governador: "De longa data se fazia sentir entre nós a necessidade de uma instituição que tivesse o objetivo humano e civilizador (...) de melhorar as condições físicas das populações ...". E mais adiante: "Mais agravava o sentimento da falta no sistema de nossa administração a existência de órgão análogo no aparelho administrativo de outros Estados (...)" (Goyaz, Mensagem ao C. Legislativo: 1927, p.44 ).

A estrutura prevista para o Serviço Sanitário goiano era de cinco delegacias — capital, Ipameri, Rio Verde, Posse e Porto Nacional — , tendo cada uma delas um certo número de inspetorias com sede em cada município. A cidade de Goiaz, capital, sediava também a Diretoria Geral de Serviço Sanitário.

As poucas verbas e os parcos recursos orçamentários destinados ao setor indicam a pouca importância e as limitações de intervenção da saúde pública em Goiás. Foram mínimos os recursos destinados nos orçamentos: em 1927, 1,38\% das despesas realizadas [62:649\$] e, em 1928, 1,18\% das despesas realizadas [59:832\$], aliás, sempre inferiores às despesas orçadas (Goyaz, Relatório Sec. Finanças, 1928, p.75).

O Serviço Sanitário teve pouco tempo de funcionamento. Logo após a
CAMPOS, F. I. Saúde Pública: a medicina e a política. Rev. Pat. Trop.25 ( 2 ): 173-186, jul./dez. 1996

vitória do Movimento de 1930, a interventoria federal o extingue (Decreto $\mathrm{n}^{\circ} \mathbf{9 7}$, 5/11/1930). Os motivos alegados para tal foram: que o situacionismo estadual utilizava-se do Serviço Sanitário como arma política contra seus adversários; que os charlatães tinham franca liberdade de ação ou eram tolerados; que, com a precária situação dos cofres públicos, estando o salário do funcionalismo com mais de dez meses de atraso, tornava-se imprescindível o desaparecimento do Serviço de Higiene (Relatório, 1930-33, p. 61). Considerando-se as razões alegadas, tem-se que nenhum outro setor da administração estadual foi extinto por questões orçamentárias; aliás, eram irrisórios os gastos com o setor de saúde. Restam dois outros motivos, especialmente o primeiro, o que leva a crer em perseguição política ao médico Pedro Ludovico.

\subsection{Pós-1930}

Poucos dias após sua investidura como interventor federal, Pedro Ludovico extingue o Serviço Sanitário, criado no governo Brasil Caiado. Noventa dias depois, em fevereiro de 1931, os serviços de saúde pública são reorganizados, passando a denominar-se Diretoria de Higiene, subordinada à Secretaria de Segurança e Assistência Pública (Dec. n 714, de 19/02/1931).

$\mathrm{O}$ referido decreto fixa as bases para a regulamentação da saúde pública, que é elaborada em seguida. Em junho vem a público o Regulamento, um extenso documento que detalha em cada item a ação do governo no setor sanitário e na saúde da população.

Na sua reorganização, uma das principais alterações havidas diz respeito ao médico: "Somente os médicos legalmente habilitados poderão exercer as atribuiçб̃es de delegados e inspetores de higiene..." (Art. 18 ${ }^{\circ}$, Dec. 714). Além disso, eles ficam isentos do imposto de indústria e profissão, "sendo-lhes permitido o serviço de clínica particular remunerada" (Art. 19\%, Dec. 714). No Regulamento, o papel do médico é destacado, seja como executor das medidas necessárias à saúde pública, seja como elaborador de conhecimento. Neste sentido, cabe aos dirigentes, normalmente médicos, proceder a estudos que forneçam elementos à compreensão da realidade social e que contribuam para melhor conhecer as doenças e os problemas da saúde da comunidade.

Outra alteração ocorrida é a centralização dos serviços de higiene. Os municípios são tratados como subordinados à autoridade da saúde pública. Exige o Regulamento que os municípios destinem $10 \%$ das rendas arrecadadas para os serviços de saúde pública, revogando, inclusive, o artigo $30, \S 4$ da Constituição Estadual. Aliás, o documento não podia ser mais claro ao afirmar que esta exigência ñ̃o fere a autonomia municipal, "uma vez que nos encontramos em pleno regime ditatorial" (Goiás, Dec.nº 1180/1931, Exposição de Motivos, p. 4).

A subordinação do município às autoridades sanitárias é clara, pois, quando trata do abastecimento de água, do sistema de esgoto e da coleta do lixo, o 
Regulamento afirma que "o município fica obrigado a submeter o projeto à Diretoria de Higiene". Em outros itens, o documento dá à autoridade sanitária poder de exigir dos dirigentes municipais o cumprimento das normas fixadas no Regulamento. Aqui, convém salientar, expressa-se, além do caráter centralizador do Estado pós-1930, a superioridade que o conhecimento médico-sanitário oferece à autoridade médica. $\mathrm{O}$ dirigente municipal se subordina não somente aos poderes estaduais, mas, principalmente, ao especialista que é conhecedor da questão sanitária (Dec. n. ${ }^{\circ}$ $1180 / 1931$, arts. 24,25 e 30 ).

Outra mudança que se verifica é a de caber ao interventor a escolha do município sede da Diretoria de Higiene, ou seja, uma escolha política e não técnica. A divisão do Estado em zonas sanitárias merece ser considerada. As cidades indicadas para sediar a Diretoria de Higiene - Anápolis, Rio Verde, Ipameri, Arraias e Natividade - são escolhas políticas. Cidades que tinham maior peso político na Primeira República, quando o Estado era dominado pelos Caiado Goyaz, Morrinhos e Porto Nacional - , passam a ser subordinadas, respectivamente, a Anápolis, a Ipameri e a Natividade. Aliás, uma das modificações havidas em 1938, na reformulação do Regulamento de saúde pública, foi quanto à mudança de sede de zona sanitária. Goyaz e Porto Nacional passam a ser sede da Diretoria de Higiene. Pedro Ludovico já consolidara seu poder no Estado.

A questão dos recursos financeiros e as limitações orçamentárias são pontos de estrangulamento da administração estadual. Os documentos do governo no período abordam as dificuldades e as carências do Tesouro estadual. Embora nos anos 30 os recursos destinados à saúde tenham percentualmente aumentado, o interventor sempre aponta a impossibilidade de uma adequada atuação do Estado no setor de saúde pública. Os recursos disponíveis destinavam-se à construção da nova capital.

A mudança da capital, em 1933, tem a ver com a 'criação' da Diretoria de Higiene e com o Regulamento de 1931. É com base no saber médico que Pedro Ludovico, interventor federal, descaracteriza a antiga capital, Goyaz, como cidade capaz de sediar o Governo. O Regulamento fornece os principais argumentos contra a cidade de Goyaz, o que chamo de 'argumento sanitário'. Ao mesmo tempo que, tendo por base o mesmo saber médico, expresso também no Regulamento, a nova capital, Goiânia, é fundada (Campos, 1980, p. 29/39).

\subsection{A reforma de 1938}

A visão que o interventor Pedro Ludovico transmite nos diferentes documentos que tratam do Serviço Sanitário do Estado é a de que ele não atinge seus objetivos, especialmente devido à falta de recursos orçamentários. Em sua mensagem ao Congresso, em 1936, afirma: "Efetivamente a atuação da Diretoria Geral do Serviço Sanitário (...) só se fez sentir, mais diretamente e com acentuada eficiência na sede do Governo" (p.31/32). As estatísticas que os diferentes documentos do período apresentam referem-se basicamente a Goiânia e, raras vezes, à cidade de Goyaz, antiga capital.

Quanto às inspetorias de Higiene, afirma claramente, em 1936, que são inexistentes: "Em seu recente relatório, o sr. dr. Diretor Geral do Serviço Sanitário manifesta francamente a sua nenhuma confiança nas atividades confiadas às Inspetorias de Higiene.” Referindo-se a esses órgãos técnicos, afirma ele de início que "células componentes destes órgãos de administração, as Inspetorias de Higiene, não desempenharam, até hoje, as funções a que estão destinadas. (p. 34).

A seguir, apresenta à Câmara dos Deputados uma proposta de reorganização do Serviço Sanitário, especialmente no que se refere às inspetorias de Higiene. Os pontos básicos da reorganização são: a) que as prefeituras assumam os gastos com prédios e instalações das inspetorias; b) que os inspetores, médicos, não sejam remunerados, que trabalhem gratuitamente. Em 1936, após tecer críticas ao serviço sanitário, o governo propõe um retorno à organização do serviço de Higiene, anterior a 1930.

Uma das modificações introduzidas em 1938 foi quanto à mudança de sede da zona sanitária. As cidades de Goyaz, antiga capital, e Porto Nacional passam a sediar a Diretoria de Higiene, tal como na Primeira República.

\section{O REGULAMENTO DA SAÚDE PÚBLICA}

A intervenção médica se faz através do Regulamento. Ele, em sua natureza, é político. Enquanto elemento de intervenção na sociedade, penetrando no mais recôndito da vida do homem, seja urbano ou rural, esquadrinha e interfere em todos os espaços sociais, tendo por base o saber médico-sanitário. Contudo, não se apresenta como tal, revestindo-se do caráter neutro do discurso legal, tendo por base o saber médico. E é exatamente este conhecimento científico que lhe garante e justifica a certeza de ser obedecido.

Consideramos a seguir dois documentos, um elaborado e editado em 1926 (Decreto 8968, de 23/4/1926), que em seus 372 artigos organiza os serviços sanitários do Estado. O outro, elaborado em 1931 (Decreto 1180), mais minucioso, em seus mais de mil artigos procura intervir e controlar, mais que o primeiro, a sociedade goiana. Em sua essência, eles não diferem quanto aos princípios de intervenção médico-sanitária; o primeiro é menos específico, mais genérico e o segundo especifica e detalha questão por questão, item por item.

Enquanto normatiza a vida e o funcionamento de diferentes setores da sociedade, o Regulamento procura, através de estatísticas demógrafo-sanitárias, via levantamento e estudos realizados pelas delegacias de Higiene, refletir sobre a realidade sanitária e sócio-econômica. Objetiva, também, conhecer melhor o Estado e aprimorar os mecanismos de intervenção na sociedade. Este conhecimento permite 
que se torne cada vez mais abrangente a ação da saúde pública. Ele expressa claramente a relação poder/saber, trabalhada por Foucault.

\subsection{O Regulamento de 1926}

A primeira preocupação do Regulamento é com a organização administrativa do serviço de saúde; mais de vinte artigos são dedicados à definição dos serviços e às atribuições de cargos e funções. Em seguida, o Regulamento trata da habilitação profissional, momento em que especifica o controle e fiscalização do exercício da medicina, da farmácia, da odontologia e da obstetrícia.

O serviço de Higiene transfere para a alçada municipal boa parte de suas atribuições, tanto na fiscalização da higiene como no controle sanitário. Contudo, não estão claramente definidas na legislação as atribuições de uma e outra instância. Pois, se no artigo $2^{\circ}$ os encargos de melhoramento higiênico e de fiscalização das construçð̃es, dos gêneros alimentícios, de fábricas e de "tudo quanto direta ou indiretamente possa influir na salubridade do município (...)" passam a ser da competência deste, o artigo $3^{\circ}$ estabelece o inter-relacionamento e a subordinação do serviço municipal à Diretoria de Higiene, estadual.

A divisão do Estado em delegacias de Saúde tem por objetivo aumentar a ação e a abrangência do serviço. São criadas cinco delegacias de Saúde, tendo por sede a capital $\left(1^{a}\right)$, Ipameri $\left(2^{a}\right)$, Rio Verde $\left(3^{a}\right)$, Posse $\left(4^{a}\right)$ e Porto Nacional $\left(5^{a}\right)$. Além disso, cada município sedia uma inspetoria sanitária. É interessante observar que o cargo de inspetor deverá ser exercido gratuitamente, tendo direito somente a ajuda de custo, quando se fizer necessário (art. $13^{\circ}$ ).

A estes inspetores sanitários, o Regulamento incumbe todos os encargos e atribuições do serviço sanitário, desde a polícia sanitária e a vigilância médica até a fiscalização de alimentos, entre outras atribuições.

Dois terços da legislação tratam da 'polícia sanitária', que também poderia ter a denominação de 'polícia médica', como se especifica a seguir. Em 231 artigos, o Regulamento detalha a construção, o funcionamento e a fiscalização da escola, da fábrica, de oficinas, mercados e matadouros; aborda a fiscalização da fabricação de diversos produtos alimentícios; trata da construção de habitações, em geral, e particulariza e a construção e o funcionamento de escolas, hospitais, açougues, bares, restaurantes etc.; também os necrotérios e cemitérios têm normas estabelecidas.

Quando trata da fiscalização de fábricas e oficinas, a legislação impõe restrições e limitações ao trabalho do menor de 12 anos e da mulher grávida. Proíbe aos menores de 18 anos e às mulheres o trabalho noturno. Na regulamentação do trabalho do menor, determina que não pode exceder a cinco horas diárias em serviços moderados que não lhes prejudiquem a saúde ou embaracem a instrução escolar (art. 103). Vale observar que não existe, ainda, uma legislação trabalhista e nem uma ação sindical ou associativa que defenda o menor ou a mulher, particularmente em Goiás.

\subsection{O Regulamento de 1931}

Tal como o Regulamento de 1926, este trata, inicialmente, da organização da Diretoria de Higiene, especificando serviços, cargos e atribuições. A diferença básica daquele é que o Regulamento de 1931 é mais longo e mais minucioso, com cerca de 1.100 artigos. O documento normatiza a casa, as ruas, a doença, as profissões, o trabalho, a escola, alimentos, hotéis e restaurantes, hospitais, farmácias, barbearias, o lixo, o esgoto, a água, as igrejas e templos. Penetra e interfere em todos os recantos e meandros da vida da população.

A pretensão do Regulamento é atingir todo o território goiano. O Estado é dividido em cinco 'zonas sanitárias', responsáveis pela política de saúde e inspeção geral em um conjunto de cidades. Um inspetor de higiene é designado para cada uma das delegacias, cabendo a ele a responsabilidade da 'política sanitária'. Para cada município, deve ser nomeado um guarda sanitário, responsável pela 'vigilância sanitária'. No texto do decreto, não é clara a distinção entre as funções do inspetor e as do guarda, pois, em geral, a referência é feita à autoridade sanitária.

O Regulamento define uma profilaxia geral que trata, entre outras coisas, das doenças transmissíveis, prevendo vacinações, cuidados e isolamento para um conjunto de 24 doenças. Define, também, a vigilância sanitária, diária e obrigatória, para os portadores das enfermidades, especificando cuidadoso controle do domicílio e pessoas próximas ao doente. Em seguida, o Regulamento define a profilaxia rural com ela, a ação da saúde pública procura abranger o campo, suas construções e atividades. Especifica, além disso, uma polícia sanitária da zona rural.

Trata, em seguida, da fiscalização do exercício das profissões de médico, farmacêutico e dentista, bem como das parteiras. Em quase cem artigos - do 494 ao 590 - é detalhada a atividade daqueles profissionais da saúde, do médico principalmente, uma vez que ele é peça fundamental tanto na ação da saúde pública como na elaboração do conhecimento. A fiscalização se estende à farmácia, ao laboratório de análise clínica, à indústria farmacêutica e à drogaria.

A higiene escolar merece no Regulamento um atenção especial. Em 58 591 a 649 - a vida da escola, do aluno, do professor e do funcionário é inspecionada. Há exigência de cuidados de higiene e asseio para ser cumpridos, bem como referências a possíveis defeitos físicos, visuais e auditivos, determinando que se afastem da escola os cegos, os surdos-mudos e os idiotas (artigo 598, $\S 1^{\circ}$ ). O prédio escolar e o professor são objetos de análises detalhadas, podendo o candidato ao magistério não ser admitido se portador de doença ou anomalia especificada em oito itens. Entre estes, afecções no ouvido, nariz, garganta, olhos, boca e dentes (numerosas cáries).

As construções recebem especificações detalhadas, desde o preparo do terreno, altura da edificação e pé direito, até questões de instalação e ventilação. Em 217 artigos, os diferentes tipos de construção são objeto de criterioso exame por parte da autoridade sanitária. Assim, o domicílio, a fábrica, a casa de banho, os 
hotéis e pensões, os hospitais e maternidades, as igrejas e templos, os prédios e logradouros públicos, escolas, barbearias, estábulos, cemitérios e necrotérios são sujeitos ao crivo da inspeção sanitária que pode, nos termos da legislação, fornecer ou não o 'habite-se'.

Os gêneros alimentícios recebem uma fiscalização especial. Em 137 artigos, os diferentes estabelecimentos que produzam ou comercializam alimentos são fiscalizados. As condições de higiene do prédio, das instalações e do pessoal são rigidamente estabelecidas pelo documento. Os alimentos recebem uma atenção especial e são passíveis de exames que comprovem ser próprios ao consumo público.

No que diz respeito a pessoal, o Regulamento procura disciplinar o trabalho do menor de 18 anos e da mulher, além de proibir o trabalho de menores de 12 anos. Além disso, traz um conjunto de exigências quanto ao local de trabalho.

O Regulamento é detalhista para cada item mencionado. Normatiza a ação sanitária, especificando cada ponto a ser obedecido na construção, na limpeza, na fabricação e nos diferentes itens de que trata. Para as infrações, prevê punições e estabelece multas a ser aplicadas pelas autoridades sanitárias.

\section{CONCLUSÃO}

Neste trabalho, procurou-se analisar a relação da medicina com a política. $\mathrm{O}$ desenvolvimento da medicina evidencia o interesse do saber médico em aproximarse do poder constituído no Estado. Torna-se claro, também, como os políticos buscam na medicina, enquanto ciência, um ponto de apoio para seus projetos, dada a força legitimadora que o saber médico contém. Assim, a relação se apresenta claramente: de um lado, a medicina penetrando no organismo social, estabelecendo o controle e buscando mais conhecimento que lhe dê maiores condições de fazê-lo; do outro, a política, que vê no saber médico um argumento de poder e de articulação de projetos, bem como uma base de legitimação consistente.

Para a demonstração empírica, examinaram-se os governos em que houve a 'criação' do serviço de saúde pública em Goiás. No primeiro, em 1926/27, a necessidade de saída da crise leva o governo goiano a procurar alternativas que the garantam apoio e lhe ofereçam condições de contrapor-se à pressão política que tende a aumentar. Não é evidente o uso do saber médico, pois há um direcionamento da ação do governo para questões sociais, o que se evidencia através da ampliação dos recursos orçamentários para educação, obras públicas e saúde. A criação do serviço sanitário no Estado de Goiás, de certo modo, obedece a uma sistemática nacional. Contudo, não se pode deixar de levar em conta os interesses da política estadual. Em 1925/26, o quadro político que se apresentava era de dificuldades, com uma crescente insatisfação. É interessante observar que, num momento em que a oligarquia tudo procurava controlar, a administração estadual chama os municípios, as intendências, para dividir os encargos do controle sanitário e da fiscalização da higiene.

Pedro Ludovico, tão logo chega ao poder, extingue aquele serviço para, em seguida, recriá-lo numa perspectiva centralizadora e mais intervencionista. Com um Regulamento mais detalhista, procura abranger e controlar a cidade, o campo, as atividades produtivas e o trabalho no Estado como um todo. A centralização esbarra na falta de recursos financeiros, humanos e administrativos do Estado de Goiás, que impedia a implementação de uma política globalizante e de natureza tão específica como a da saúde pública. Daí se poder questionar a eficácia desta estratégia de intervenção, o Regulamento de Saúde Pública. Neste sentido, convém salientar que a 'reforma de 1938' é de certo modo um retorno à organização adotada quando da criação do serviço de saúde pública em 1926.

Foi, contudo, o Regulamento e seu detalhismo que ofereceram o suporte científico para o discurso oficial que retira da cidade de Goiás as condições para continuar sendo capital, ao mesmo tempo que serve de base à construção de uma nova cidade, destinada a ser a sede do governo - Goiânia. A construção de Goiânia fornece a base do poder e da liderança do interventor Pedro Ludovico. No início dos anos 30, é apoiando-se na construção da nova cidade que ele se firma como principal líder político goiano. Tendo como bandeira a construção de Goiânia, Pedro Ludovico, nos anos em que se mantém no poder, constrói uma sólida estrutura política que, a partir de 1945, configura-se na máquina política pessedista. Com base nela, ele controla o Executivo e o Legislativo estaduais até quase 1965.

Seria simplismo fazer do Regulamento da Saúde Pública o único suporte do poder e prestígio de Pedro Ludovico - ele deve ser entendido como um dos mecanismos e estratégias utilizados. É conveniente salientar que o médico Pedro Ludovico utiliza o saber médico como instrumento de poder. No entanto, uma das modificações básicas do Regulamento de 1931, elaborado por inspiração dele, vai ser a de reforçar o papel político do médico. Há um veemente apelo à 'classe médica' para que coopere com a Diretoria de Higiene na execução de seu plano de ação, ao mesmo tempo que a valorização da medicina e de seus profissionais passa a ser o eixo da saúde pública.

\section{SUMMARY}

\section{Public Health: medicine and politics}

The transformation of medicine in the XVIII and XIX centuries in relation with the knowledge about human beings, make it broadest - environment, nature, society - and with a social involvement, hence, a science of the social. Medical knowledge turns to be a power instrument and a means of legitimization. 
Medical knowledge will be a pathway to obtain social knowledge and to dominate through the Public Health. The foundation of the Sanitary Service in the State of Goias (1920/1940) is used to explain this process, trying to show the influence of the medicine upon the society, that establish a political control and is used as a power instrument.

KEYWORDS: Public health. Medicine. Politics.

\section{REFERÊNCIAS BIBLIOGRÁFICAS}

01.Berlinguer, Giovanni. Medicina e politica. São Paulo, Cebes-Hucitec, 1983.

02.Carrion, Rejane M. M. "Politização da Medicina 'versus' Medicalização da Política. Rev. de Cultura e Política, $\mathrm{n}^{\circ}$ 4. Rio de Janeiro, Paz e Terra, 1981 41-47.

03.Campos, F. Itami. Mudança da capital: uma estratégia de poder. Cadernos do INDUR n 2 . Goiânia, F. Indur, 1980: 29-39.

04.Campos, F. Itami. Coronelismo em Goiás. Goiânia. Cegraf/UFG, 1983.

05.Chaul, Nasr N. F. A construção de Goiânia e a transferência da capital. Goiânia, Cegraf/UFG, 1988.

06.Donnangelo, M.C. \& PEREIRA, Luiz. Saúde e sociedade. São Paulo, Duas Cidades, 1976.

07.Estado de Goyaz. Mensagem ao Congresso, 1927.

08.Estado de Goyaz. Relatório Secretario das Finanças. 1928.

09.Estado de Goyaz. Relatório Secretário das Finanças. 1929.

10.Estado de Goyaz. Correio Official. No $1158,1159,1160,1168$.

11.Estado de Goyaz. Relatório ao Presidente da República, 1930/33.

12.Estado de Goyaz. Mensagem ao Congresso, 1936.

13.Estado de Goyaz. Decretos n 8968/1926; 1180/1931.

14.Foucault, Michel. Microfisica do poder. Rio de Janeiro, Graal, 1979.

15.Foucault, Michel. O nascimento da clínica. Rio de Janeiro, Forense - Universitária, 1977.

16.Guimarães, Reinaldo (org.). Saúde e medicina no Brasil. Rio de Janeiro, Graal, 1984.

17.Luz, T. Madel. As instituições médicas no Brasil. Rio de Janeiro, Graal, 1979.

18.Machado, Maria Cristina T. Pedro Ludovico: um tempo, um carisma, uma história. Goiânia, Cegraf/UFG, 1990.

19.Machado, Roberto e Outros. Danação da norma: a medicina social e a constituição da psiquiatria no Brasil. Rio de Janeiro, Graal, 1978.

20.Merhy, Emerson Elias. A saúde pública como politica. São Paulo, Hucitec, 1992. 